
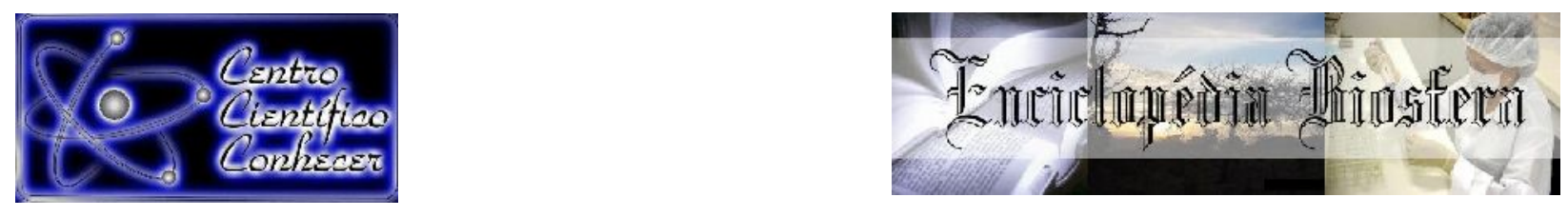

\title{
DIVERSIDADE CULTURAL DE CEPAS DE ACTINOBACTÉRIAS ORIUNDAS DE ÁREAS SUSCETÍVEIS À DESERTIFICAÇÃO
}

Franciandro Dantas dos Santos ${ }^{1}$, Mariane Pereira Oliveira ${ }^{2}$, Valéria Maria Araújo Silva $^{3}$, Suzana Cláudia Silveira Martins ${ }^{4}$, Claudia Miranda Martins ${ }^{5}$

1. Doutorando do Programa de Pós-graduação em Ecologia e Recursos Naturais na Universidade Federal do Ceará-Campus do Pici, Fortaleza-CE, Brasil. androdsantos@gmail.com

2. Graduanda do Curso de Bacharelado em Agronomia na Universidade Federal do Ceará-Campus do Pici, Fortaleza-CE, Brasil.

3. Doutoranda do Programa de Pós-graduação em Ecologia e Recursos Naturais na Universidade Federal do Ceará-Campus do Pici, Fortaleza-CE, Brasil.

4. Docente na Universidade Federal do Ceará-Campus do Pici, Fortaleza-CE, Brasil.

5. Docente na Universidade Federal do Ceará-Campus do Pici, Fortaleza-CE,Brasil.

Recebido em: 06/04/2019 - Aprovado em: 10/06/2019 - Publicado em: 30/06/2019 DOI: 10.18677/EnciBio_2019A142

Desertos são ambientes extremos caracterizados por condições adversas. No Brasil, as áreas mais susceptíveis à desertificação se localizam na região do semiárido nordestino e, diversas pesquisas estão demonstrando a importância de actinobactérias em serviços ecossistêmicos no semiárido. Em actinobactérias típicas, o micélio pode ser dividido em aéreo e reverso. A observação das cores desses micélios é um dos primeiros métodos utilizados para a distinção de isolados e considerados um parâmetro fundamental para a identificação desses microorganismos. Considerando-se a relevância de actinobactérias na região semiárida, objetivou-se comparar a diversidade cultural desse grupo microbiano em três áreas suscetíveis à desertificação, classificadas de acordo com o nível de cobertura vegetal. A diversidade cultural foi observada nas três áreas, sendo mais expressiva na área intermediária.

PALVRAS-CHAVE: Cobertura vegetal, Semiárido, serviços ecossistêmicos,

\section{CULTURAL DIVERSITY OF ACTINOBACTERIA STRAINS OF AREAS SUSCEPTIBLE TO DESERTIFICATION}

\begin{abstract}
Deserts are extreme environments characterized by adverse conditions. In Brazil, the areas most susceptible to desertification are located in the northeastern semiarid region, and several researches are demonstrating the importance of actinobacteria in ecosystem services in the semiarid region. In typical actinobacteria, the mycelium can be divided into aerial and reverse. Color observation of these mycelia is one of the first methods used to distinguish isolates and is considered a key parameter for the identification of these microorganisms. Considering the relevance of actinobacteria in the semiarid region, the objective was to compare the cultural
\end{abstract}


diversity of this microbial group in three areas susceptible to desertification, classified according to the level of vegetation cover. Cultural diversity was observed in the three areas, being more expressive in the intermediate area.

KEYWORDS: Semiarid, Ecosystem Services, vegetation cover.

\section{INTRODUÇÃO}

A desertificação é um problema de dimensões globais que afeta as regiões de clima árido, semiárido e subúmido seco da Terra (BRASIL, 2006). No Brasil, as áreas mais susceptíveis à desertificação se localizam na região do semiárido nordestino (INSA, 2012), onde $94 \%$ da área é considerada com moderada à alta suscetibilidade à desertificação (VIEIRA et al., 2015).

Desertos são ambientes extremos caracterizados por condições adversas, tais como aridez, intensa radiação solar UV e mudanças bruscas de temperatura entre a noite e o dia (JÚLIA et al., 2016). Além disso, os desertos apresentam oligotrofia crônica, ou seja, a vegetação vascular esporádica e as crostas microbiológicas desempenham papéis cruciais na produção primária deste ecossistema (HAWKES; FLECHTNER, 2002). Esse tipo de vegetação, bem como as crostas microbiológicas auxiliam na emolduração e estruturação da comunidade bacteriana do micro ecossitema desses solos (SUN et al., 2015).

Ambientes desertícos são típicos de ecossistemas hostis, cuja disponibilidade de água afeta diretamente os organismos. Assim sendo, microorganismos xerofílicos, adaptados a elevadas temperaturas e altos níveis de radiação, são as populações provavelmente predominantes nesses ecossistemas, incluindo filos como Actinobacteria, Proteobacteria e Bacteroidetes, geralmente resistentes à radiação e dissecação (VIKRAM et al., 2016).

Diversas pesquisas apontam a ocorrência de actinobactérias em solo da região semiárida (BRITO et al., 2015; SILVA et al., 2015; ALVES et al., 2016 LOPES et al., 2018; MEDEIROS et al., 2018; SOUSA et al., 2018). Além disso, estudos com destaque para a produção de enzimas que auxiliam na facilitação, processo ecológico que desempenha importante papel em ambientes degradados, também já foram documentados nesse ambiente (SILVA et al., 2019). Por outro lado, interações antagônicas entre actinobactérias e rizóbios oriundos do semiárido, que podem impactar diretamente na fixação biológica de nitrogênio, foram descritas por Lima et al., (2017) e Cavalcante et al., (2017).

Actinobactérias são caracterizadas como aeróbias ou microaerófilas, (EMBLEY; STACKEBRANT, 1994); são Gram-positivas com elevada concentração de guanina e citosina no DNA (RAO et al., 2012). São abundantes na natureza e dispersas em diversos ambientes, sendo o solo seu hábitat principal (MANSOUR et al., 2015) onde são importantes componentes da comunidade microbiana, desempenhando funções como fixação de amônio, decomposição de tecido celular e síntese do húmus (BHATTI et al., 2017).

Em actinobactérias típicas, o micélio pode ser dividido em aéreo e reverso. (LI et al., 2016), esses micélios são filamentosos e possuem hifas aéreas, cuja principal função é a absorção de nutrientes para o crescimento desses microorganismos (BHATTI et al., 2017). A observação das cores do micélio aéreo e lado reverso (produção de pigmentos) é um dos primeiros métodos usados para a distinção de isolados e são considerados aspectos fundamentais para a identificação de actinobactérias (MABROUK, SALEH, 2014, AMSAVENI et al., 2015).

Considerando-se a variedade de actinobactérias na região semiárida, objetivou-se comparar a diversidade cultural desses micro-organismos em três áreas 
suscetíveis à desertificação, classificadas de acordo com o nível de cobertura vegetal. Salienta-se ainda que essa heterogeneidade de culturas foi registrada através de imagens, de forma a colaborar nos estudos desse grupo.

Área de estudo

\section{MATERIAL E MÉTODOS}

As amostras de solo foram provenientes de áreas suscetíveis à desertificação com diferentes níveis de cobertura vegetal (área aberta, intermediária e conservada). Esse local representa uma mancha inserida na microrregião do Médio Jaguaribe e localizada entre os municípios de Jaguaribe, Jaguaretama e Morada Nova, totalizando uma área de $3239.40 \mathrm{~km}^{2}$. O clima dessa região é caracterizado como quente e seco, com precipitações médias de aproximadamente $800 \mathrm{~mm}$, por ano. Apresenta um período seco frequentemente caracterizado pela falta de chuvas, temperaturas médias anuais entre 23 e $27^{\circ} \mathrm{C}$ e insolação média de $2.800 \mathrm{~h}$ ano-1 (SUDENE, 2019). Todas as amostras foram gentilmente cedidas pelo projeto Desert (Evolução da perda de biodiversidade em áreas sob processos de degradação), chamada de Projetos MEC/MCTI/CAPES/CNPq/FAPs Nº 03/2014.

\section{Actinobactérias}

Foram selecionadas 24 cepas (08 de cada área) a partir de 47 isoladas do solo do Médio Jaguaribe, tendo como principal requisito a diversidade quanto ao aspecto cultural. As cepas foram previamente codificadas como "MJ", indicativo de Médio Jaguaribe, seguido pelo número (MJ01-MJ47). As cepas de actinobactérias selecionadas foram: MJ-01, MJ-06, MJ-10, MJ-14, MJ-29, MJ-32, MJ-33, MJ-36 (área aberta), MJ-02, MJ-03, MJ-07, MJ-08, MJ-18, MJ-19, MJ-37, MJ-38 (área intermediária), MJ-25, MJ-26, MJ-27, MJ-40, MJ-43, MJ-44, MJ-45 e MJ-47 (área conservada). Essas cepas são mantidas em tubos com meio caseína dextrose (CD), a $25^{\circ} \mathrm{C}$ no Laboratório de Microbiologia Ambiental (LAMAB) do Departamento de Biologia da Universidade Federal do Ceará, compondo a Coleção de Cultura de Actinobactérias do Semiárido.

\section{Cultivo das cepas}

As cepas selecionadas foram inoculadas em placas de Petri em meio CDA, com a seguinte composição para $1000 \mathrm{~mL}: 0,5 \mathrm{~g}$ de $\mathrm{K}_{2} \mathrm{HPO}_{4}, 0,2 \mathrm{~g}$ de $\mathrm{MgSO}_{4} .7 \mathrm{H}_{2} \mathrm{O}$ (sulfato de magnésio), $2 \mathrm{~g}$ de glicose, $0,01 \mathrm{~g}$ de $\mathrm{FeSO}_{4} .7 \mathrm{H}_{2} \mathrm{O}$ (sulfato de ferro), $0,2 \mathrm{~g}$ de caseína (previamente dissolvida em $10 \mathrm{~mL}$ de $\mathrm{NaOH}$ 0,1N), $15 \mathrm{~g}$ de ágar, e 2,5 $\mathrm{mL}$ de nistatina (antifúngico). $\mathrm{O} \mathrm{pH}$ foi ajustado para 6,5 6,6. As cepas foram posteriormente inoculadas em caldo $\mathrm{CD}$ e incubadas a $28^{\circ} \mathrm{C} \mathrm{em}$ mesa agitadora a $150 \mathrm{rpm}$ por 14 dias. As placas foram incubadas em B.O.D. a $28^{\circ} \mathrm{C}$ por 14 dias.

As actinobactérias foram também inoculadas no centro da placa com o auxílio de uma alça de platina para obter colônias com diâmetro maior a fim de facilitar o registro por meio de foto, bem como para classificar a forma das colônias. As placas foram incubadas em B.O.D. a $28{ }^{\circ} \mathrm{C}$ por 14 dias, em seguida, realizou-se o registro fotográfico.

Caracterização cultural

Cada cepa foi inoculada por estrias em placas de Petri, após purificação, contendo o meio seletivo CDA para actinobactérias. Em seguida as placas foram incubadas em estufa B.O.D a $28 \pm 2{ }^{\circ} \mathrm{C}$ por um período de sete a 14 dias. Para descrição das características culturais foram avaliadas as cores do micélio aéreo e 
reverso das colônias, baseada na carta de cores (RAL color charts) e o formato das colônias de acordo com Augustine et al. (2013).

Registro fotográfico

As fotos foram realizadas com as placas abertas em câmara de fluxo laminar, para dar um melhor contraste, com plano de fundo preto. As fotografias das cepas foram captadas em planos superior e inferior, para melhor visualização, enquanto, que para as colônias isoladas foi escolhido apenas o plano superior com o auxílio de uma lente micro angular (For Digital Camera \& Mobile Phone LENS).

\section{RESULTADOS E DISCUSSÃO}

A diversidade cultural das cepas oriundas da microrregião do Médio Jaguaribe pode ser observada pelos gráficos em forma de pizza (Figuras 1, 2, 3 e 4) e pelo registro fotográfico, que abrange imagens das placas de Petri com enfoque no micélio aéreo e em colônias isoladas (Figura 5).

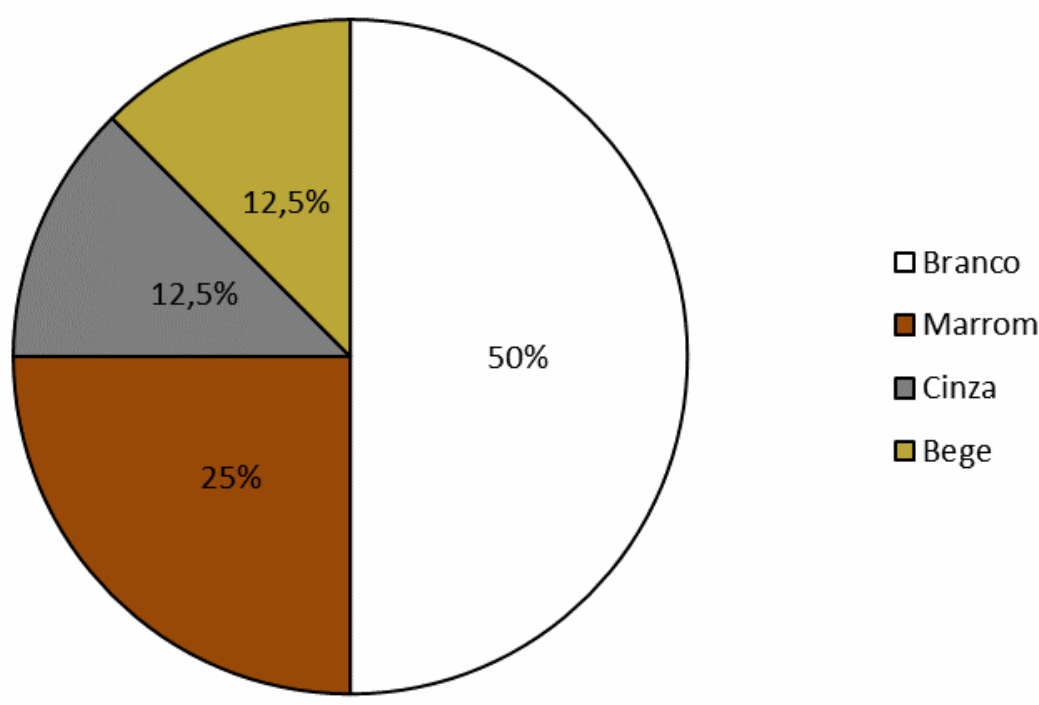

FIGURA 1: Diversidade cromogênica de actinobactérias oriundas da microrregião do Médio Jaguaribe na área aberta. 


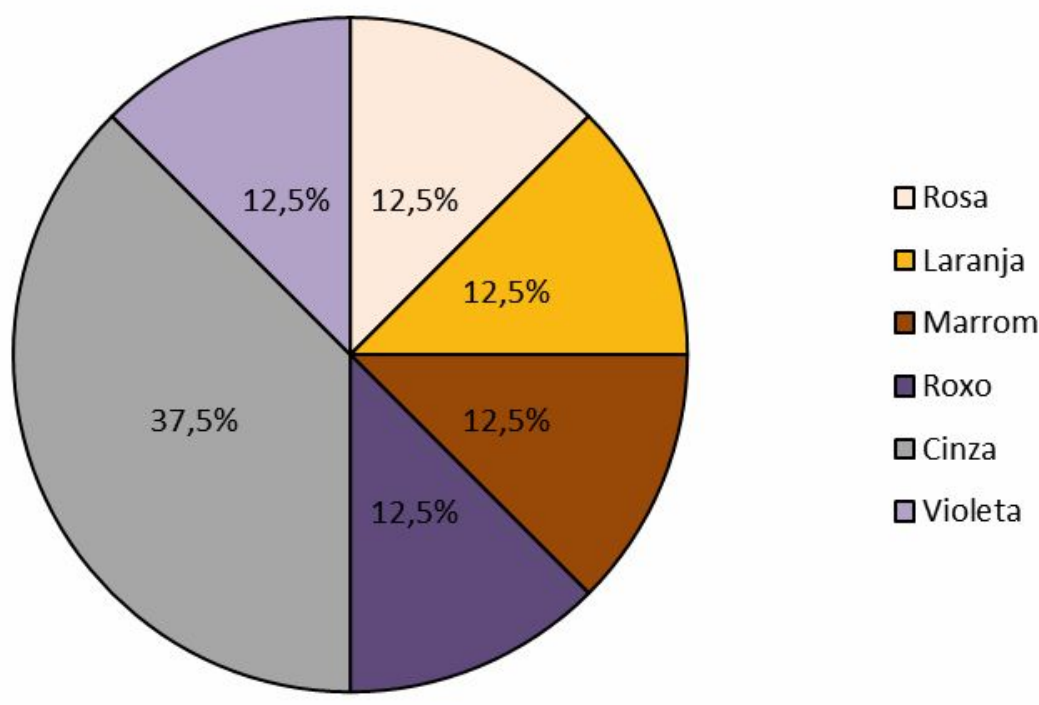

FIGURA 2: Diversidade cromogênica de actinobactérias oriundas da microrregião do Médio Jaguaribe na área intermediária.

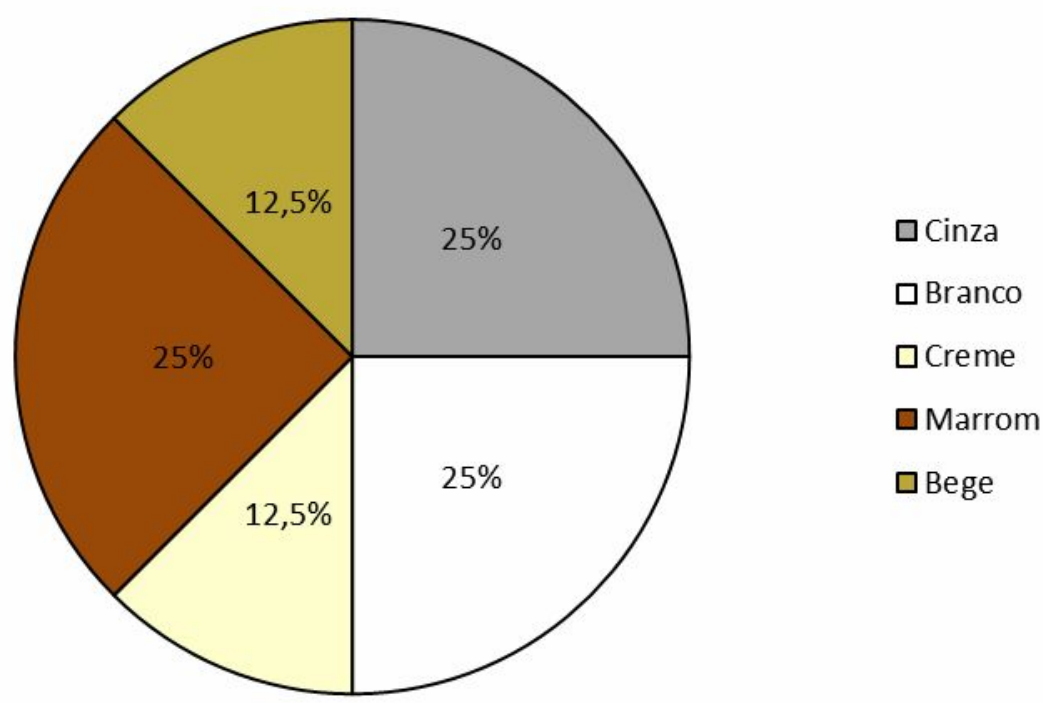

FIGURA 3: Diversidade cromogênica de actinobactérias oriundas da microrregião do Médio Jaguaribe na área conservada.

Houve diferença entre as cepas em relação à cor do micélio aéreo, demonstrando a diversidade cultural desse grupo. As actinobactérias são reconhecidas pela produção de variados pigmentos, que podem estar presentes dissolvidos no meio, ou mesmo retidos em seus micélios (AMSAVINI et al., 2015). Apesar da produção de pigmentos não ser considerada imprescindível para o crescimento microbiano, acredita-se que exerce importante função ecológica, colaborando para a sobrevivência e competitividade dos micro-organismos (SHARMA, 2014; OLIVEIRA et al., 2014).

Neste trabalho, as colorações marrom e branco foram predominantes nas áreas aberta e conservada, semelhante ao trabalho de Medeiros et al. (2018), que ao estudarem a diversidade cromogênica de actinobactérias no semiárido constataram predominância para as cores marrom e amarela. De forma similar, ENCICLOPÉDIA BIOSFERA, Centro Científico Conhecer - Goiânia, v.16 n.29; p. 1848 2019 
Ramos et al. (2015) ao caracterizarem culturalmente cepas de actinobactérias oriundas do semiárido, observaram que a cor branca se sobressaiu em relação as demais. Por outro lado, na área intermediária a cor cinza prevaleceu, aproximandose dos resultados obtidos por Silva et al. (2015), que, ao caracterizarem a variedade de cores das colônias de actinobactérias no semiárido, obtiveram um total de $39 \%$ para essa mesma cor.

Diante do exposto, é possível constatar diferenças culturais entre as cepas de actinobactérias nas três áreas estudadas, porém de forma mais expressiva na área intermediária. Esse fato pode ser explicado pela teoria do distúrbio intermediário, pois segundo essa hipótese, níveis intermediários de perturbações tendem a promover maior diversidade (CONNEL, 1978).

As cepas de actinobactérias apresentaram diferença em relação ao aspecto da colônia (Figura 4). O formato das colônias variou de aveludado com 37\% (09 cepas), concêntrico com 25\% (06 cepas), umbonado com 17\% (04 cepas), sulcos radiais com 13\% (03 cepas) e convexo com apenas $8 \%$ (02 cepas). (Figura 5,6 e 7). Até o presente momento, ainda não há registros na literatura em relação a essa classificação na região semiárida brasileira, entretanto, variação similar foi constatada por Augustine et al. (2013), ao realizarem estudo com actinobactérias oriundas de ambientes marinhos provenientes da Costa Sudoeste e Sudeste da Índia.

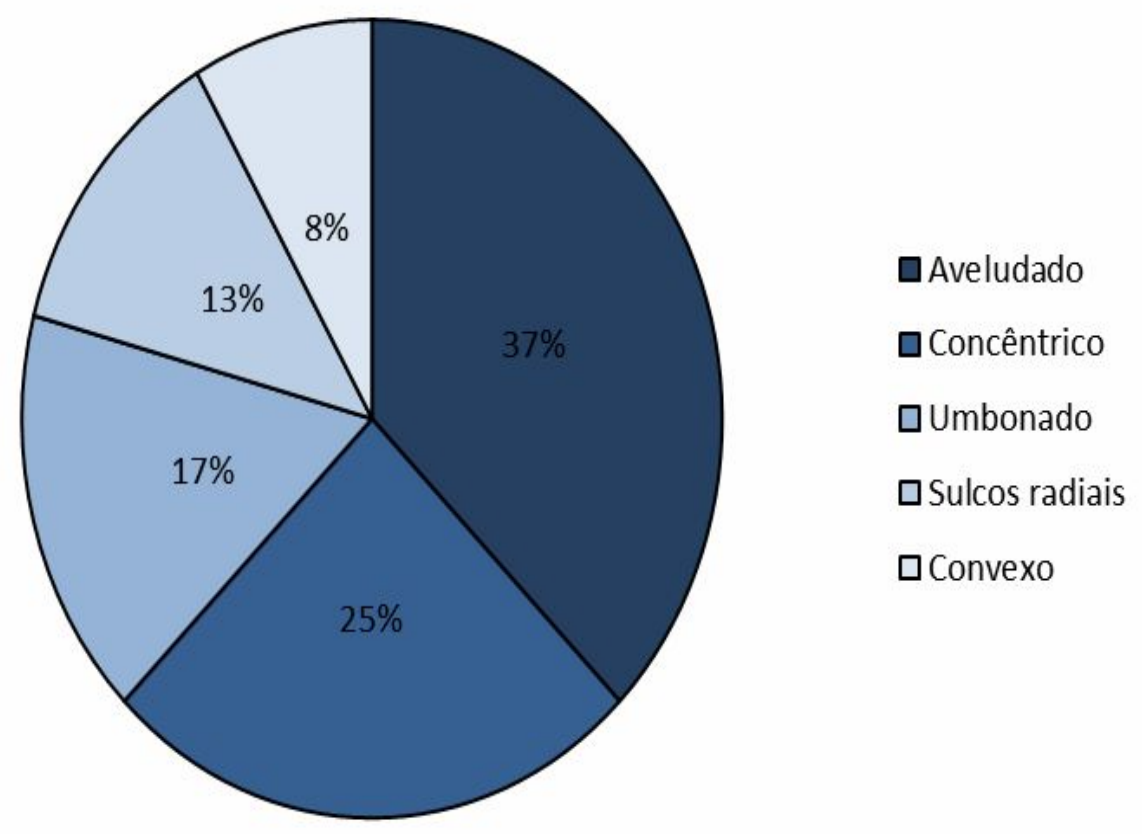

FIGURA 4: Aspectos das colônias de actinobactérias oriundas da microrregião do Médio Jaguaribe nas áreas aberta, intermediária e conservada. 


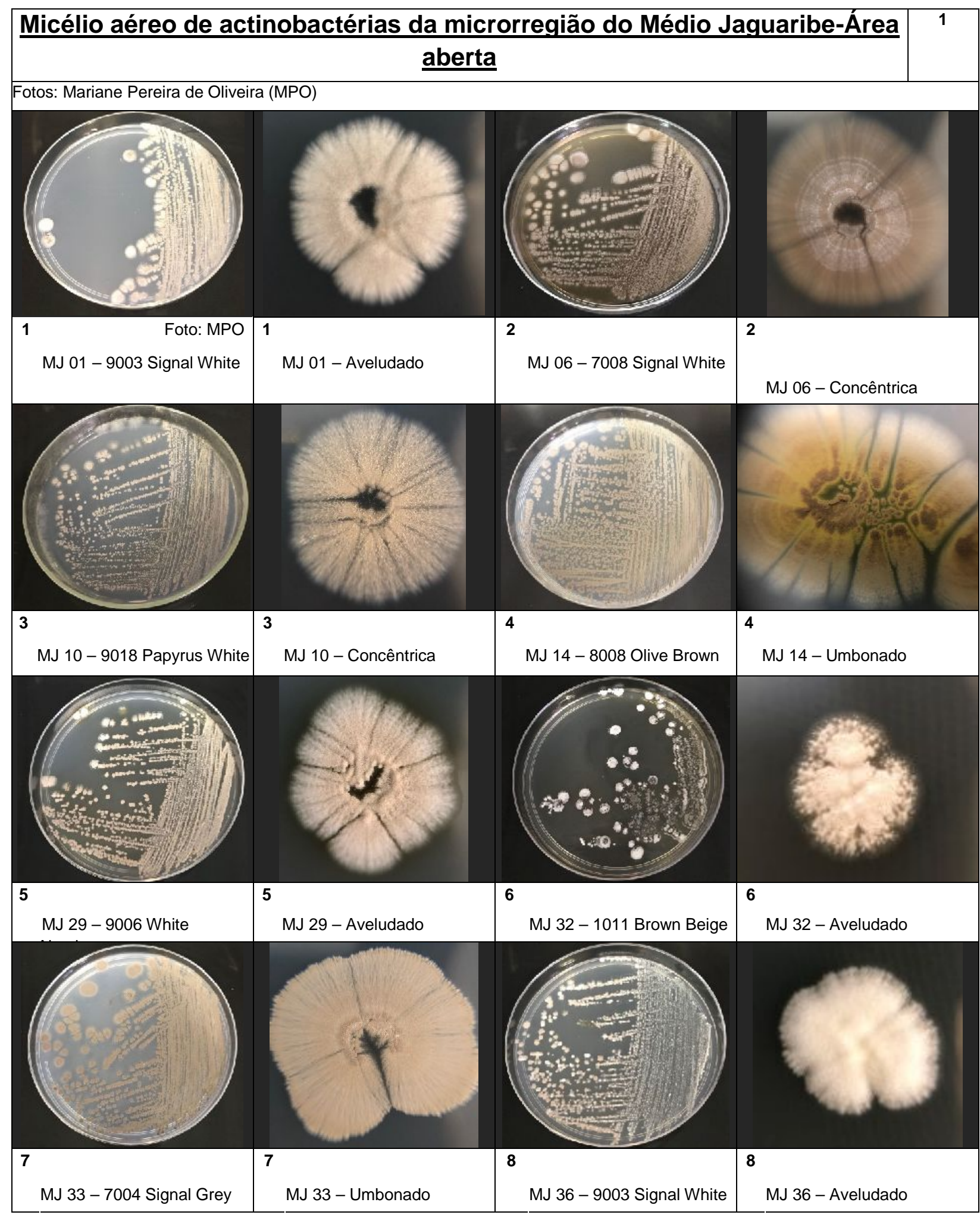

FIGURA 5: Registro fotográfico do micélio aéreo e de colônias isoladas de cepas de actinobactérias oriundas da microrregião do Médio Jaguaribe na área aberta. 


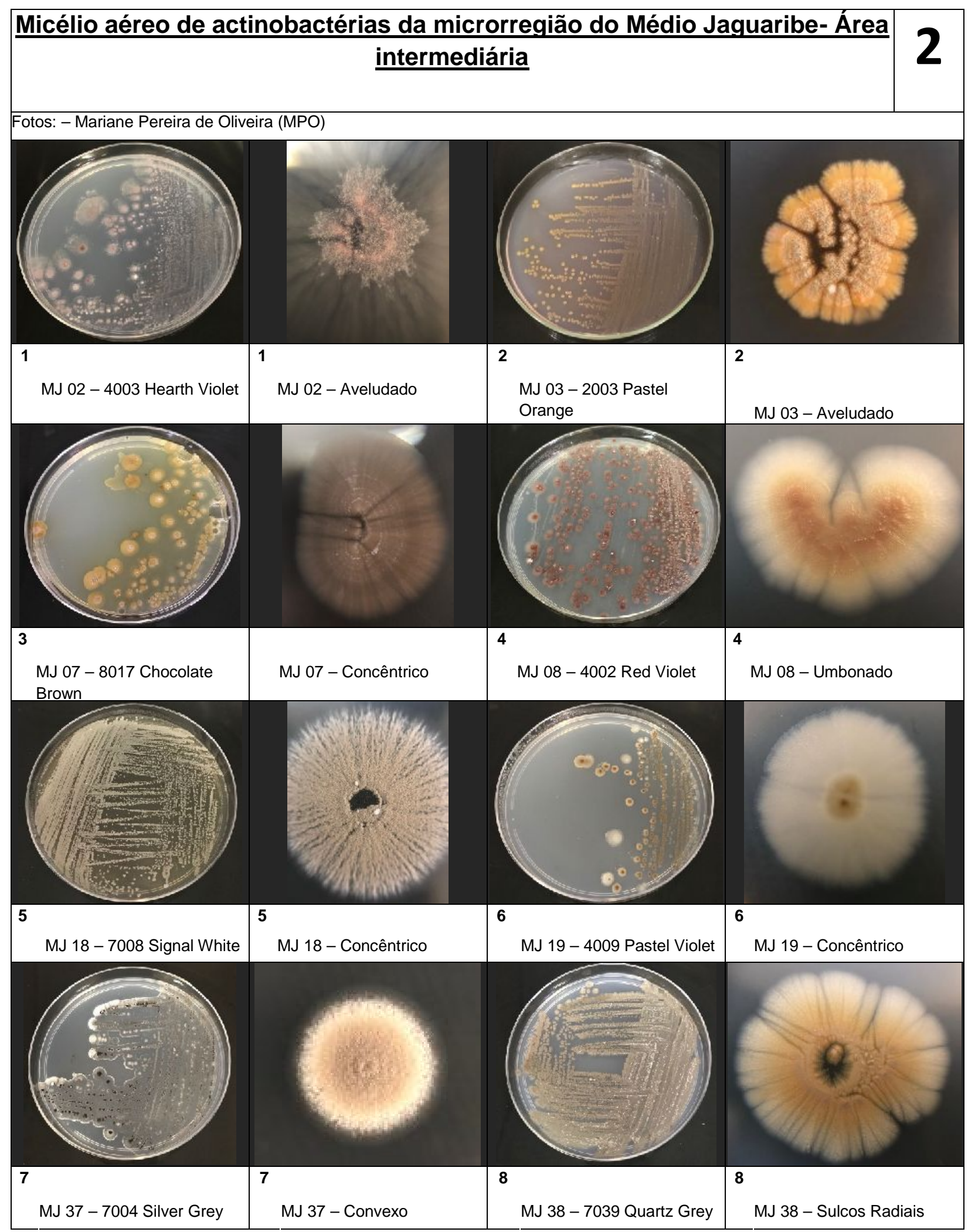

FIGURA 6: Registro fotográfico do micélio aéreo e de colônias isoladas de cepas de actinobactérias oriundas da microrregião do Médio Jaguaribe na área intermediária. 


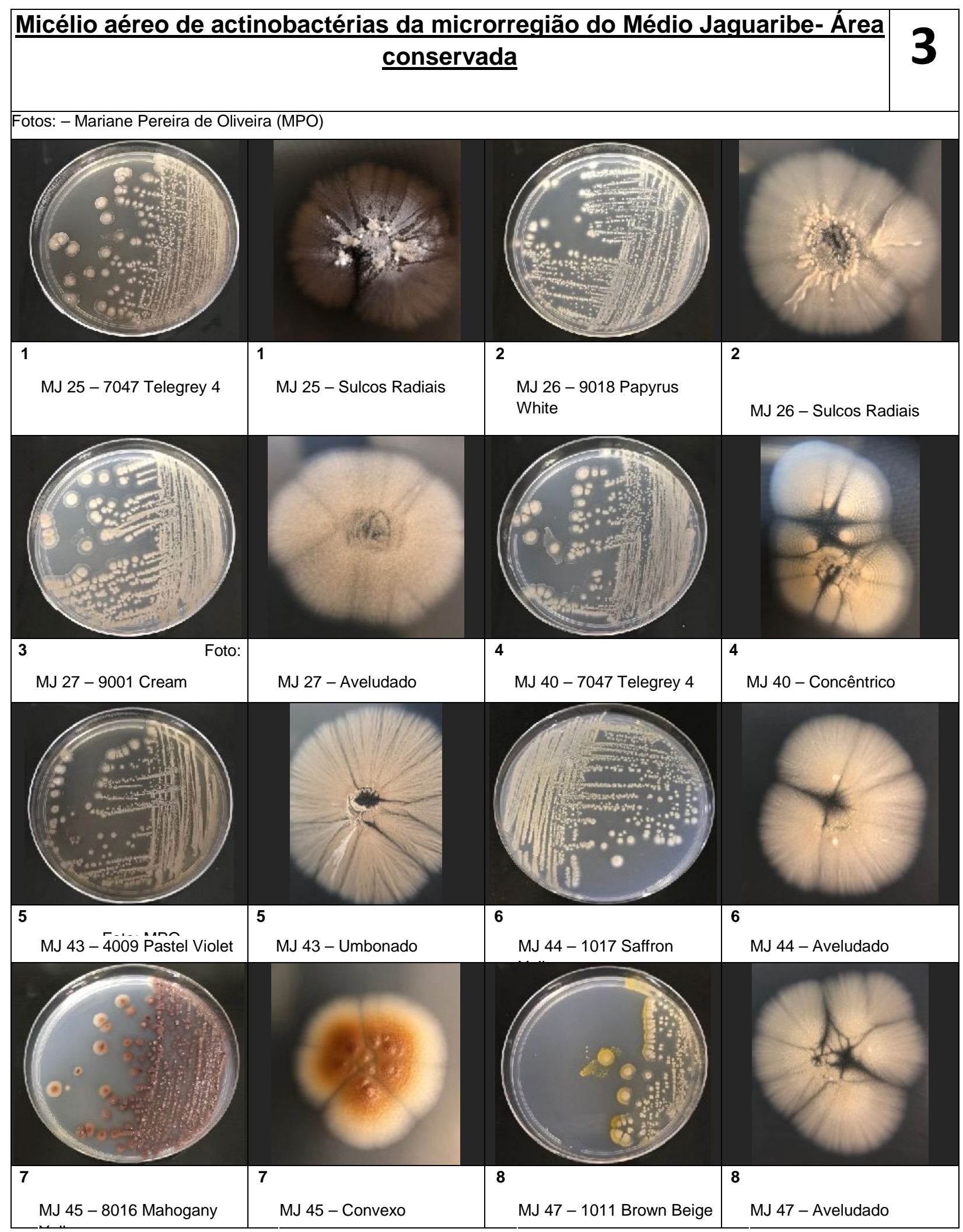

FIGURA 7: Registro fotográfico do micélio aéreo e de colônias isoladas de cepas de actinobactérias oriundas da microrregião do Médio Jaguaribe na área conservada. 


\section{CONCLUSÃO}

A diversidade cultural entre as cepas de actinobactérias foi observada nas três áreas com diferentes níveis de cobertura vegetal, porém de forma mais expressiva na área intermediária. Ademais, o formato das colônias pode ser utilizado como um parâmetro a mais para classificação cultural desse grupo. Consequentemente, o material produzido poderá ser utilizado como ferramenta na caracterização de novas cepas provenientes da região semiárida.

\section{AGRADECIMENTOS}

O presente trabalho foi realizado com apoio da Coordenação de Aperfeiçoamento de Pessoal de Nível Superior-Brasil (CAPES)-Código de Financiamento 001.

\section{REFERÊNCIAS}

ALVES, D. A. S.; SILVA, V. M. A.; GARCIA. F. A. C.; MARTINS, S. C. S.; MARTINS, C. M. Produção de celulase e amilase por actinobactérias do semiárido brasileiro. Enciclopédia Biosfera, v.13 n.24; p.1303-1315, 2016. Disponível em: https://drive.google.com/drive/u/0/folders/1S0vMIDP3LBfOX3HvZpg0d5hzRFfBDDE2

AMSAVENI, R.; SURESHKUMAR, M.; VIVEKANANDHAN, G.; BHUVANESHWARI, V.; KALAISELVI, M. Screening and isolation of pigment producing Actinomycetes from soil samples. International Journal of Biosciences and Nanosciences, v.2, p.24-28. 2015. Disponível em: < http://ijbsans.com/archives/journal15/feb15/1_MS15-104.pdf>

AUGUSTINE, D., JACOB, J. C., RAMYA, K.; PHILIP, R. Actinobacteria from sediment samples of Arabian Sea and Bay of Bengal: biochemical and physiological characterization. Internacional Journal of Research in Marine Sciences. v.2, p.5663. 2013.

BHATTI, A. A.; HAQ, S.; BHAT, R. A. Actinomycetes benefaction role in soil and plant health. Microbial Pathogenesis, v. 111, p.458-467, 2017. Disponível em: <https://doi.org/10.1016/j.micpath.2017.09.036>. doi: 10.1016/j.micpath.2017.09.036.

BRITO, F. A. E.; RAMOS, K. A.; DA SILVA, R. M. ; MARTINS, C. M.; MARTINS, S. C. S. Actinobacteria from rizospheric soil in the caatinga biome. Enciclopédia $\begin{array}{llllll}\text { Biosfera, } & \text { v. } & 11, & \text { p. } & 1992-2004, & 2015 .\end{array}$ Disponível http://www.conhecer.org.br/enciclop/2015b/biologicas/actinobacterias.pdf

em:

CAVALCANTE, F. G., MARTINS, C. M.; MARTINS, S. C. S. Interações bióticas entre actinobactérias e rizóbios em solos da região semiárida brasileira. Enciclopédia Biosfera, v.14 n.26; p. 2017. Disponível em: < http://www.conhecer.org.br/enciclop/2017b/biol/interacoes\%20Bioticas.pdf> DOI: 10.18677/EnciBio_2017B86

CONNELL, J. H. Diversity in Tropical Rain Forests and Coral Reefs. Science, v. 199, n. $4335, \quad$ p. 1302-1310, 1978. Disponível em: <http://science.sciencemag.org/content/199/4335/1302/tab-pdf> DOI: 10.1126/science.199.4335.1302. 
EMBLEY, T. M.; STACKEBRANDT, E. The Molecular phylogency and systematics of the Actinomycetes. Annual Review of Microbiology, v. 48, 1994.

HAWKES, C. V.; FLECHTNER, V. R. Biological soil crustsin a xeric Florida shrubland: composition, abundance, and spatial heterogeneity of crusts with different disturbance histories. Microbial Ecology. v.43, n.1 p.1-12, 2002. Disponível em:<https://doi.org/10.1007/s00248-001-1017-5> DOI: $10.1007 / \mathrm{s} 00248-001-1017-5$

INSA. Sinopse do Censo Demográfico para o Semiárido Brasileiro. Medeiros, S. de S. et al. Campina Grande, 2012. 103p.

JÚLIA, M. A.; GERGELY, K.; DÓRA, A.; KÁROLY, M.; BALÁZS, N.; ANDREA, K. B. Diversity of extremophilic bacteria in the sediment of high-altitude lakes located in the mountain desert of Ojos del Salado volcano, Dry-Andes. Extremophiles v.20, 603-620, 2016. Disponível em: < https://scihub.tw/10.1007/s00792-016-0849-3> DOI: 10.1007/s00792-016-0849-3

LI, Q.; CHEN, X.; JIANG, Y.; CHENGLIN, J. Morphological Identification of Actinobacteria. Actinobacteria - Basics and Biotechnological Applications, [s.l.],p.59-86, 2016. Disponível em: <https://doi.org/10.5772/61461 >. DOI: $10.5772 / 61461$.

LIMA, J. V. L.; MARTINS, S. C. S; SIQUEIRA, K. A.; SOARES, M.; MARTINS, C. M. Characterization of actinobacteria from the semiarid region, and their antagonistic effect on strains of rhizobia. African Journal of Biotechnology. v.16, p.499-507, 2017. Disponível em: <https://doi.org/10.5897/AJB2016.15724> DOl: 10.5897/AJB2016.15724

LOPES, J. B. A. C., SILVA, V. M. A., CAVAlCANTE, F. G., MARTINS, S. C. S., MARTINS, C. M. Produção de enzimas hidrolíticas extracelulares por actinobactérias oriundas do solo e serrapilheira de região semiárida. Enciclopédia Biosfera, v. 15, n. 27, p. 35-50, 2018.2 Disponível em: <http://www.conhecer.org.br/enciclop/2018a/biol/producao.pdf> DOI: 10.18677/EnciBio_2018A93.

MABROUK, M. I.; SALEH, N. M. Molecular identification and characterization of antimicrobial active actinomycetes strains from some Egyptian soils. American Eurasian Journal Agriculture \& Environment Science, v.14, p.954-963. 2014. Disponível em: <https://www.researchgate.net/profile/Neveen_Saleh/publication/281349>DOI: 10.5829/idosi.aejaes.2014.14.10.8641

MANSOUR, S. R.; ABDEL-AZEEM, A. M.; ABO-DERAZ, S. S. S. A new record of Actinobacteria isolated from soil in Jerusalem and their enzymatic potential. F1000Research, v.4.2015. Disponível em: <https://f1000research.com/articles/4-11> DOI

MEDEIROS, E. J. T.; CAVALCANTE, F. G.; SILVA, V. M. A.; SILVEIRA, S. C.; MARTINS, C. M. Diversidade cultural de cepas de actinobactérias do semiárido. 
Enciclopédia Biosfera, v.15, p.205-218. 2018. Disponível em: < http://www.conhecer.org.br/enciclop/2018a/biol/diversidade.pdf> DOI: 10.18677/EnciBio_2018A87

OLIVEIRA, A. P. G.; SABINO, S. M.; GANDINE, S. M.; MOULIN, T.; AMARAL, A. A. Importância das actinobactérias em processos ecológicos, industriais e econômicos. Enciclopédia Biosfera, v.10, n.18; p.3938-3952, 2014. Disponível em: http: <www.conhecer.org.br/enciclop/2014a/MULTIDISCIPLINAR/importancia.pdf>

RAO, K. R., KIRAN, C. R., RAO, D. B., MADHAVI, Y., RAO, P. K., \& RAO, T. R. Antagonistic activities of actinobacteria from mangrove sediment. International Journal of Pharmacy and Pharmaceutical Sciences, v.4, n.1, 2012. Disponível em: <https://www.researchgate.net/publication/270865687>

RAMOS, K. A.; BRITO, F. A. E.; NUNES, K. J. F.; MARTINS, C. M.; MARTINS, S. C.S. Caracterização e diversidade cromogênica de actinobactérias de um nicho microbiano preservado do bioma caatinga. Enciclopédia Biosfera, v. 11, p.21152125, 2015. Disponível em: < http://www.conhecer.org.br/enciclop/2015b/biologicas/caracterizacao\%20e \%20diversidade.pdf>

SHARMA, M. Actinomycetes: Source, identification, and their applications. International Journal of Current Microbiology and Applied Science. v.3, n.2, p.801-832, 2014. Disponível em: < https://www.researchgate.net/publication/292100429_Actinomycetes_Source_identifi cation_and_their_applications>

SILVA, V. M. A.; LIMA, J. V. L; GONDIM, P. M..; MARTINS, C. M; SUZANA, C. S. M. Effect of irrigation and type of cultivation on richness and diversity of chromogenic actinobacteria of soil from Ceará semiarid region. Enciclopédia Biosfera, v. 11, p.2965-2979, 2015. Disponível em: < https://www.researchgate.net/publication/316278948_Characterization_of_actinobact eria_from_the_semiarid_region_and_their_antagonistic_effect_on_strains_of_rhizobi a>

SILVA, V. M. A; MARTINS, C. M.; CAVALCANTE, F. G.; RAMOS, K. A.; SILVA, L. L. et al. Cross-Feeding Among Soil Bacterial Populations: Selection and Characterization of Potential Bio-inoculants. Journal of Agricultural Science, v. 11, n, 5. 2019 (no prelo). URL: https://doi.org/10.5539/

SOUSA, J. B; LIRA, I. C; MARTINS, S. C. S; MARTINS, C. M. Efeito da antropização sobre a produção da enzima xilanase em actinobactérias. Enciclopédia Biosfera, v.15 n.28; p. 2018. DOI: 10.18677/EnciBio_2018B84

SUDENE.<http://www.sudene.gov.br/acesso-a

informa\%C3\%A7\%C3\%A3o/institucional/area-de-atuacao-da sudene/semiarido> Acesso em: 28/03/2019.

SUN, H. M.; ZHANG, T.; YU, L. Y.; KEYA, S.; ZHANG, Y. Q. Ubiquity, diversity and physiological characteristics of Geodermatophilaceae 
in Shapotou National Desert Ecological Reserve. Frontiers in Microbiology, v. 6, p. 1059, 2015. Disponível em: < https://doi.org/10.3389/fmicb.2015.01059>

VIEIRA, R. D. S. P.; TOMASELLA, J.; ALVALÁ, R. C. S.; SESTINI, M. F.; AFFONSO, A. G., et al. Identifying areas susceptible to desertification in the Brazilian northeast. Solid Earth, v.6, n.1, p.347-360, 2015. Disponível em: < https://doi.org/10.5194/se-6-347-2015>

VIKRAM, S.; GUERRERO, L. D.; MAKHALANYANE, T. P.; LE, P. T.; SEELY, M.; COWAN, D. A. Metagenomic analysis provides insights into functional capacity in a hyperarid desert soil niche community. Environmental Microbiology. v.18, n.6, p.1875-1888, 2016. Disponível em: <https://doi.org/10.1111/1462-2920.13088> 